\title{
Feasibility of ADL Test Construction Based on IRT
}

\author{
Takahiro Nakano", Takahiko Nishijima ${ }^{* *}$, and Keisuke Ohtsuka ${ }^{* * * *}$ \\ * Doctoral Program in Health and Sports Sciences, University of Tsukuba \\ taka@stat.taiiku.tsukuba.ac.jp \\ ${ }^{* *}$ Institute of Health and Sport Sciences, University of Tsukuba \\ *** Master's Program in Health and Physical Education, University of Tsukuba \\ 1-1-1 Tennodai, Tsukuba, Ibaraki 305-8574 Japan \\ [Received January 15, 2004 ; Accepted July 1, 2004]
}

\begin{abstract}
The purpose of this study was to examine the feasibility of constructing a new test by analyzing the item characteristic of motor function and physical independence ADL tests based on the item response theory (IRT). Subjects were 137 males and 198 females, aged over 65 years old. The average of age was $69.2 \pm 5.4$ years old (male $70.4 \pm 5.5$, female 68.7 \pm 5.2 ). The physical independence and the motor function ADL test were consisted of 15 items with 2 options. Unidimesionality of physical independence and motor function ADL tests were satisfied for item characteristic analysis. Item difficulty and item discrimination were calculated by using two-parameter logistic model. Item characteristic curves, item information functions, test characteristic curves, and test information functions were obtained from the item difficulty and the item discrimination. In the new test, $70 \%$ of the whole subjects were able to achieve $80 \%$ or more based on the item characteristic. The item difficulty, the item discrimination, and the amount of item information of each item were confirmed. Eighty $\%$ of the whole subjects were able to achieve $80 \%$ or more in physical independence ADL test. Fifty $\%$ of the whole subjects were able to achieve $80 \%$ or more in motor function ADL test. It was concluded that the new test satisfied target test characteristics could be composed from previous test items applying IRT techniques.
\end{abstract}

Keywords: Item characteristic analysis, Test character, adaptive testing

[International Journal of Sport and Health Science Vol.2, 145-155, 2004]

\section{Introduction}

Activities of Daily Living (ADL) are important indices for measuring the physical and mental health of the elderly. Lawton $(1969,1970)$ has defined ADL as all activities seen daily from getting up to going to bed apart from jobs and recreational activities. Many ADL scales have been proposed [Mahoney and Barthel, (1965); Katz, et al., (1963); Katz, et al., (1970)] and have been used to measure survival ability of impaired elderly as well as to measure functional recovery in rehabilitation [Barer and Nouri, (1989)]. Other trends include studies on the development of scales of extended ADL to measure basic ability of living activities adjusted to various life environments by adding the scale of instrumental independence ability (instrumental ADL) [Meer and Baker, (1966)] to the conventional scales of ADL. [Asberg and Sonn, (1988); Fillenbaum, (1985); Kempen and Suurmeijer, (1990); Sonn and Asberg, (1991); Spector, et al., (1987)]. Also, a test of functional ADL has been developed [Pfeffer, et al., (1982)] that can measure ability in higher level activities better than instrumental ADL. The ability of living functions of the elderly can be measured using these ADL scales.

In these ADL scales, however, there is a tendency that many elderly can easily obtain full marks [Jette and Branch, (1981)]. In the instrumental ADL and the functional ADL, these issues are somewhat resolved, but we cannot 
be sure of the actual state. In this sense, it is necessary to select proper measuring items to realize a valid ADL measurement and to develop a test component with difficulty in accordance with the level of subjects. There is a study that has clarified item characters of a compound ADL scale that mixed a physical independence ADL scale with a functional ADL scale [Spector and Fleishman, (1998)]. Merits to show the item characters of the ADL test items are to describe test characteristic, to give a guideline of the test component, and to permit development of tests to measure a wide variety of ADL by creating adaptive tests in future [Shibayama, et al., (1987)]. Also, it may allow a new direction for the evaluation of ADL tests. Conventional evaluation of ADL tests is represented by a method showing the ability by the items [Rusk, (1977)], a method calculating general index [Mahoney and Barthel, (1965)], or a method showing the ability of representative activities [Potivin, (1972)].

Evaluative methods formerly proposed have some problems. First, they tend to have too many items because of their nature to investigate all daily activities. This problem can be solved by creating an adaptive test previously noted. Second, they have a problem of digitization of evaluation. As we shall later describe, the use of the item response theory (IRT) [Lord, (1952); Rasch, (1980); Hattori, (1986); Hambleton and Swaminathan, (1985)] permits constant evaluation of the ability of subjects in the same scale. Third is the issue of evaluative subjects. The test in accordance with the level of subjects can be created by explaining characteristics of each item. Further, by adopting IRT, ability evaluation in the same scale is possible even when the evaluative subject is changed. This enables evaluation in the same scale even if the test is reconstructed according to the purpose.

For these reasons, it is quite significant to clarify item characteristic and test characteristic of instrumental ADL, functional ADL, and higher-level social interaction ADL and motor function $\mathrm{ADL}$ in addition to physical independence
ADL. For analysis of item character, IRT, which has been developed from classical test theories, is frequently used in recent years. The advantages of IRT are characterized by three descriptions by Hambleton and Swaminathan (1985). (1) Assuming the existence of a large pool of items all measuring the same trait, the estimate of an examinee's ability is independent of the particular sample of the test items that are administered to the examinee, (2) assuming the existence of a large population of examinees, the descriptors of a test item (for example, item difficulty and discrimination indices) are independent of the particular sample of examinees drawn for the purpose of calibrating the item, and (3) a statistic indicating the precision with which each examinee' $\mathrm{s}$ ability is estimated is provided. Because of these merits, we consider it quite effective to construct an ADL test based on the result of analysis of item characters using IRT.

Grounded on these points, the purpose of the present study is to seek for the possibility of creating a new test based on IRT by analyzing item characteristic and test characteristic of the physical independence ADL test and the motor function ADL test of the elderly.

\section{Method}

\subsection{Subjects}

The total number of subjects is 335,137 males and 198 females, of local area elderly over 60 years of age. Age of males averaged $70.4 \pm 5.48$ years old, and females averaged $68.7 \pm 5.24$ years old, with the average of $69.2 \pm 5.35$ years old as a whole.

\subsection{Measuring Method}

For measurement items, based on the content validity, 15 selective items were used from the physical independence ADL of the elderly. Also, based on the content validity, 15 items for selection were used from the motor function ADL. 
Table 1 Measurement items

\begin{tabular}{|c|c|c|c|}
\hline Domain & $\begin{array}{c}\text { Item } \\
\text { number }\end{array}$ & Question & $\begin{array}{c}\text { Answer } \\
\text { form }\end{array}$ \\
\hline $\begin{array}{c}\text { Physical } \\
\text { independence } \\
\text { ADL }\end{array}$ & $\begin{array}{l}\text { P_ADL-1 } \\
\text { P_ADL-2 } \\
\text { P_ADL-3 } \\
\text { P_ADL-4 } \\
\text { P_ADL-5 } \\
\text { P_ADL-6 } \\
\text { P_ADL-7 } \\
\text { P_ADL-8 } \\
\text { P_ADL-9 } \\
\text { P_ADL-10 } \\
\text { P_ADL-11 } \\
\text { P_ADL-12 } \\
\text { P_ADL-13 } \\
\text { P_ADL-14 } \\
\text { P_ADL-15 }\end{array}$ & $\begin{array}{l}\text { Getting up from the bed without asistance } \\
\text { Changing clothes } \\
\text { Washing oneself completely without back } \\
\text { Down stairs without assistance } \\
\text { Washing clothes } \\
\text { Preparing meal } \\
\text { Writing the letter } \\
\text { Using the remote controller of television and video } \\
\text { Moving outdoors } \\
\text { Doing storoll and physical exercise } \\
\text { Ride on the bicycle } \\
\text { Moving outdoors using the vehicle without asistance } \\
\text { Talking to young people from oneself } \\
\text { Joining the town association } \\
\text { Playing sports }\end{array}$ & $\begin{array}{l}\text { Yes } \\
\dot{\text { No }}\end{array}$ \\
\hline $\begin{array}{l}\text { Motor } \\
\text { function } \\
\text { ADL }\end{array}$ & $\begin{array}{l}\text { M_ADL-1 } \\
\text { M_ADL-2 } \\
\text { M_ADL-3 } \\
\text { M_ADL-4 } \\
\text { M_ADL-5 } \\
\text { M_ADL-6 } \\
\text { M_ADL-7 } \\
\text { M_ADL-8 } \\
\text { M_ADL-9 } \\
\text { M_ADL-10 } \\
\text { M_ADL-11 } \\
\text { M_ADL-12 } \\
\text { M_ADL-13 } \\
\text { M_ADL-14 } \\
\text { M_ADL-15 }\end{array}$ & $\begin{array}{l}\text { Walking without rest for one hour or more } \\
\text { Running without rest for ten minutes or more } \\
\text { Jumping over the ditch of } 50 \text { centimeters } \\
\text { Up stairs without using the walls and handrail } \\
\text { Standing up from sitting straight without using hands } \\
\text { One-leg open-eye stand for thirty seconds or more } \\
\text { Standing without hanging on anything with vehicle } \\
\text { Changing clothes while standing } \\
\text { Multiply by one hand and remove a front button of the shirt } \\
\text { Raising and lowering of heavy futon } \\
\text { Carrying the luggage of ten kilograms by ten meters } \\
\text { Sitting up without using hands five times or more } \\
\text { Up stairs to the fourth floor without rest } \\
\text { Opening the PET bottle and the can juice } \\
\text { Standing up from a squat posture without using hands }\end{array}$ & $\begin{array}{c}\text { Yes } \\
\dot{\text { No }}\end{array}$ \\
\hline
\end{tabular}

The answering method was two-selection of 'Yes' or 'No'. Selected items are shown in Table 1.

Physical ADL items mainly consisted of daily living activities: transfer, feeding, dressing, bathing, communication and self-care.

The items of motor function ADL consisted of such life-related activities as going out and walking, and motor functions such as balance and basic muscle strength.

\subsection{Statistical Analysis}

\subsubsection{Treatment of Non-Response Value}

We considered the reasons for most non-responses were that the respondents could not understand the content or the respondents had never performed the activities in question before. So we classified all non-responses as 'impossible.' Also, there were no subjects whose non-response rate was great in all items. Therefore we used all subjects for our analysis.

\subsubsection{Deletion of Items}

Since we judged items marked $100 \%$ in the item passive rate to be improper as part of the tests, we excluded these items from analysis of item character.

In IRT, there are two important premises of local independence and unidimensionality in the test items [Ohtomo, et al., (1987)]. 'Local independence is a hypothesis that the rate in which a subject can answer correctly to a certain item will not affect the rate in which the subject can correctly answer other items. Statistically, any answer to each of the items and the subjects are independent of each other. Unidimensionality of a test is a hypothesis that test items measure a common ability. We judged that each response to the test items in the present study was independent in its content. To verify unidimensionality, a one-factor analysis using the polychoric correlation matrix was performed in each ADL field [Takane and Leeuw, (1987)]. To extract factors, the maximum likelihood method was used.

Significance of correlation coefficient between the test scores and the items was checked. From the result of one-factor analysis, items that could not obtain more than 0.4 in the factor loadings 
Table 2 Passing rateof each item

\begin{tabular}{|c|c|c|c|}
\hline Domain & $\begin{array}{c}\text { Item } \\
\text { number }\end{array}$ & Question & $\begin{array}{c}\text { Passive rate } \\
(\%)\end{array}$ \\
\hline \multirow{15}{*}{$\begin{array}{c}\text { Physical } \\
\text { independence } \\
\text { ADL }\end{array}$} & P_ADL-1 & Getting up from the bed without asistance & 99.4 \\
\hline & P_ADL-2 & Changing clothes & 98.8 \\
\hline & P_ADL-3 & Washing oneself completely without back & 99.7 \\
\hline & P_ADL-4 & Down stairs without assistance & 100.0 \\
\hline & P_ADL-5 & Washing clothes & 97.9 \\
\hline & P_ADL-6 & Preparing meal & 96.1 \\
\hline & P_ADL-7 & Writing the letter & 96.4 \\
\hline & P_ADL-8 & Using the remote controller of television and video & 94.6 \\
\hline & P_ADL-9 & Moving outdoors & 99.7 \\
\hline & P_ADL-10 & Doing storoll and physical exercise & 98.8 \\
\hline & P_ADL-11 & Ride on the bicycle & 91.3 \\
\hline & P_ADL-12 & Moving outdoors using the vehicle without asistance & 96.1 \\
\hline & P_ADL-13 & Talking to young people from oneself & 95.2 \\
\hline & P_ADL-14 & Joining the town association & 93.7 \\
\hline & P_ADL-15 & Playing sports & 86.3 \\
\hline \multirow{15}{*}{$\begin{array}{c}\text { Motor } \\
\text { function } \\
\text { ADL }\end{array}$} & M_ADL-1 & Walking without rest for one hour or more & 76.4 \\
\hline & M_ADL-2 & Running without rest for ten minutes or more & 51.0 \\
\hline & M_ADL-3 & Jumping over the ditch of 50 centimeters & 84.2 \\
\hline & M_ADL-4 & Up stairs without using the walls and handrail & 88.4 \\
\hline & M_ADL-5 & Standing up from sitting straight without using hands & 74.0 \\
\hline & M_ADL-6 & One-leg open-eye stand for thirty seconds or more & 74.3 \\
\hline & M_ADL-7 & Standing without hanging on anything with vehicle & 72.2 \\
\hline & M_ADL-8 & Changing clothes while standing & 91.6 \\
\hline & M_ADL-9 & Multiply by one hand and remove a front button of the shirt & 87.8 \\
\hline & M_ADL-10 & Raising and lowering of heavy futon & 85.4 \\
\hline & M_ADL-11 & Carrying the luggage of ten kilograms by ten meters & 81.5 \\
\hline & M_ADL-12 & Sitting up without using hands five times or more & 46.9 \\
\hline & M_ADL-13 & Up stairs to the fourth floor without rest & 59.4 \\
\hline & M_ADL-14 & Opening the PET bottle and the can juice & 97.9 \\
\hline & M_ADL-15 & Standing up from a squat posture without using hands & 80.0 \\
\hline
\end{tabular}

and items that could not obtain significantly high correlation with test scores were excluded from the item character analysis. The level of statistical significance was $\alpha=0.1$.

\subsubsection{Analysis of Item Character}

For analysis of item character, we used a two-parameter logistic model. This model is expressed by the following formula.

$$
P_{j}(\theta)=\frac{1}{1+\exp \left(-D a_{j}\left(\theta-b_{j}\right)\right)}
$$

Here, $\mathrm{D}$ is the constant 1.7 and $\mathrm{P}_{j}(\theta)$ is the rate in which the subject with ability $\theta$ can correctly answer in a certain item $j$. ' $a$ ' is the item discrimination power parameter and is equivalent to the slope in the ability value $\theta=b$, when the model formula is expressed in graph. It means that the power to discriminate a subject with the ability of around $\theta=b$ is stronger as ' $a$ ' becomes bigger. ' $b$ ' is the item difficulty parameter and shows the difficulty of an item. The correct answer ratio of a subject whose ability value $\theta$ is equivalent to the item difficulty is always $50 \%$. In IRT, the relation among the ability of subjects, item difficulty, and correct answer ratio is shown by the Item Characteristic Curve (ICC).

\subsubsection{Analysis of Test Characteristic}

Test characteristic can be shown by the Test Characteristic Curve (TCC) and Test Information Function (TIF). TCC is computed as a sum of ICC of each item in a test. The test difficulty and the test discrimination power are computed using TCC. Change in the component items of the test can change the test characteristic. TIF can be computed as a sum of the Item Information Function (IIF) and calculated by the following formula:

$$
I I F=D^{2} \times a^{2} \times p \times(1-p)
$$

\section{Result}

\subsection{Item Passive Rate}

Table 2 shows the passive rate of each 
Table 3-1 1 Factory model (Physical independence ADL Test)

\begin{tabular}{lc}
\hline Item & $\begin{array}{c}\text { Physical } \\
\text { independence } \\
\text { ADL }\end{array}$ \\
\hline P_ADL-1 & 0.84 \\
P_ADL-2 & 0.82 \\
P_ADL-3 & 0.99 \\
P_ADL-5 & 0.67 \\
P_ADL-6 & 0.68 \\
P_ADL-7 & 0.67 \\
P_ADL-8 & 0.39 \\
P_ADL-9 & 0.99 \\
P_ADL-10 & 0.67 \\
P_ADL-11 & 0.23 \\
P_ADL-12 & 0.60 \\
P_ADL-13 & 0.47 \\
P_ADL-14 & 0.50 \\
P_ADL-15 & 0.41 \\
\hline Contibution & 45.31 \\
rate of factor (\%) & \\
\hline
\end{tabular}

Table 4-1 Correration between Physical independence ADL test score and item score

\begin{tabular}{lc}
\hline Item & $\begin{array}{c}\text { Correlation } \\
\text { coefficient }\end{array}$ \\
\hline P_ADL-1 & $0.18^{* *}$ \\
P_ADL-2 & $0.32^{* *}$ \\
P_ADL-3 & $0.35^{* *}$ \\
P_ADL-5 & $0.43^{* *}$ \\
P_ADL-6 & $0.57^{* *}$ \\
P_ADL-7 & $0.48^{* *}$ \\
P_ADL-8 & $0.08^{* *}$ \\
P_ADL-9 & $0.35^{* *}$ \\
P_ADL-10 & $0.23^{* *}$ \\
P_ADL-11 & $0.03^{* *}$ \\
P_ADL-12 & $0.45^{* *}$ \\
P_ADL-13 & $0.40{ }^{* *}$ \\
P_ADL-14 & $0.51^{* *}$ \\
P_ADL-15 & 0.60 \\
\hline
\end{tabular}

Table 3-2 1 Factory model (Motor Function ADL Test)

\begin{tabular}{lc}
\hline Item & $\begin{array}{c}\text { Motor } \\
\text { function } \\
\text { ADL }\end{array}$ \\
\hline M_ADL-1 & 0.68 \\
M_ADL-2 & 0.45 \\
M_ADL-3 & 0.80 \\
M_ADL-4 & 0.86 \\
M_ADL-5 & 0.69 \\
M_ADL-6 & 0.53 \\
M_ADL-7 & 0.74 \\
M_ADL-8 & 0.73 \\
M_ADL-9 & 0.58 \\
M_ADL-10 & 0.71 \\
M_ADL-11 & 0.60 \\
M_ADL-12 & 0.44 \\
M_ADL-13 & 0.79 \\
M_ADL-14 & 0.35 \\
M_ADL-15 & 0.79 \\
\hline Contibution & 44.33 \\
rate of factor (\%) & \\
\hline
\end{tabular}

Table 4-2 Correration between Motor function ADL test score and item score

\begin{tabular}{|c|c|}
\hline Item & $\begin{array}{c}\text { Correlation } \\
\text { coefficient }\end{array}$ \\
\hline M_ADL-1 & $0.54^{* *}$ \\
\hline M_ADL-2 & $0.48^{* *}$ \\
\hline M_ADL-3 & $0.57^{* *}$ \\
\hline M_ADL-4 & $0.59^{* *}$ \\
\hline M_ADL-5 & $0.53^{* *}$ \\
\hline M_ADL-6 & $0.43^{* *}$ \\
\hline M_ADL-7 & $0.62^{* *}$ \\
\hline M_ADL-8 & $0.47^{* *}$ \\
\hline M_ADL-9 & $0.41^{* *}$ \\
\hline M_ADL-10 & $0.51^{* *}$ \\
\hline M_ADL-11 & $0.54^{* *}$ \\
\hline M_ADL-12 & $0.31^{* *}$ \\
\hline M_ADL-13 & $0.58^{* *}$ \\
\hline M_ADL-14 & $0.12^{*}$ \\
\hline M_ADL-15 & $0.52^{* *}$ \\
\hline
\end{tabular}

item. Every item of physical independence ADL of the elderly showed a high passive rate. The mean passive rate was $96 \%$, which was an easily achievable item group. The passive rate of one item of physical independence ADL-4, 'Down stairs without assistance', was $100 \%$ so this item was excluded from analysis of item character. The mean passive rate of motor function ADL was $77 \%$. The minimum passive rate was $47 \%$ obtained in the motor function ADL-12 and the maximum passive rate was $98 \%$ in the motor function ADL-14.

\subsection{Test Unidimensionality}

The result of one-factor analysis is shown in Table 3-1 and Table 3-2. In one-factor analysis in the items of physical independence ADL, physical independence ADL-8 and physical independence ADL-11 had factor loadings below 0.4. In one-factor analysis in the items of motor function ADL, factor loading of motor function ADL-14 was below 0.4.

The correlation coefficient between the test scores and the item values is shown in Table 4-1 and Table 4-2. In the items of physical independence ADL, the correlation coefficient of physical independence ADL-8 and physical independence ADL-11 with the test scores was not significant. In the items of motor function ADL, only motor function ADL-14 did not obtain 
Table 5-1 1 Factor model after item selection (Physical independence ADL Test)

\begin{tabular}{lc}
\hline Item & $\begin{array}{c}\text { Physical } \\
\text { independence } \\
\text { ADL }\end{array}$ \\
\hline P_ADL-1 & 0.83 \\
P_ADL-2 & 0.83 \\
P_ADL-3 & 0.96 \\
P_ADL-5 & 0.69 \\
P_ADL-6 & 0.70 \\
P_ADL-7 & 0.66 \\
P_ADL-9 & 0.96 \\
P_ADL-10 & 0.68 \\
P_ADL-12 & 0.59 \\
P_ADL-13 & 0.48 \\
P_ADL-14 & 0.52 \\
P_ADL-15 & 0.43 \\
\hline Contibution & 51.01 \\
rate of factor (\%) & \\
\hline
\end{tabular}

Table 5-2 1 Factor model after item selection (Motor Function ADL Test)

\begin{tabular}{lc}
\hline Item & $\begin{array}{c}\text { Motor } \\
\text { function } \\
\text { ADL }\end{array}$ \\
\hline M_ADL-1 & 0.68 \\
M_ADL-2 & 0.46 \\
M_ADL-3 & 0.79 \\
M_ADL-4 & 0.86 \\
M_ADL-5 & 0.70 \\
M_ADL-6 & 0.53 \\
M_ADL-7 & 0.74 \\
M_ADL-8 & 0.74 \\
M_ADL-9 & 0.58 \\
M_ADL-10 & 0.70 \\
M_ADL-11 & 0.58 \\
M_ADL-12 & 0.43 \\
M_ADL-13 & 0.81 \\
M_ADL-15 & 0.79 \\
\hline Contibution & 46.65 \\
rate of factor (\%) &
\end{tabular}

significant correlation. These results showed that physical independence ADL-8, physical independence ADL-11, and motor function ADL-14 were judged to be items that could not be secured in unidimensionality, and were excluded from item character analysis.

The result of one-factor analysis after deleting these items is shown in Table 5-1 and Table 5-2. All factor loadings were more than 0.4 , which showed that they could secure unidimensionality. The correlation coefficient between the test scores in physical independence ADL and motor function ADL after item deletion was significant $(p<0.05)$, so all -27 items of unidimensionality were secured.

\subsection{Item Character}

The item difficulty and the item discrimination power are shown in Table 6. All items of physical

Table 6 Item parameter of newly test

\begin{tabular}{|c|c|c|c|c|c|c|}
\hline Domain & $\begin{array}{c}\text { Item } \\
\text { number }\end{array}$ & Question & $\begin{array}{c}\text { Item } \\
\text { difficulty }\end{array}$ & $\begin{array}{l}\text { Standard } \\
\text { error }\end{array}$ & $\begin{array}{c}\text { Item } \\
\text { discriminati }\end{array}$ & $\begin{array}{c}\text { Standard } \\
\text { error }\end{array}$ \\
\hline \multirow{12}{*}{$\begin{array}{c}\text { Physical } \\
\text { independence } \\
\text { ADL }\end{array}$} & P_ADL-1 & Getting up from the bed without asistance & -3.549 & 0.574 & 0.835 & 0.384 \\
\hline & P_ADL-2 & Changing clothes & -3.015 & 0.356 & 0.735 & 0.230 \\
\hline & P_ADL-3 & Washing oneself completely without back & -4.541 & 1.613 & 1.235 & 0.707 \\
\hline & P_ADL-5 & Washing clothes & -2.452 & 0.228 & 0.490 & 0.146 \\
\hline & P_ADL-6 & Preparing meal & -2.146 & 0.188 & 0.591 & 0.133 \\
\hline & P_ADL-7 & Writing the letter & -2.671 & 0.362 & 1.049 & 0.259 \\
\hline & P_ADL-9 & Moving outdoors & -4.349 & 1.250 & 1.114 & 0.598 \\
\hline & P_ADL-10 & Doing storoll and physical exercise & -3.187 & 0.399 & 0.885 & 0.228 \\
\hline & P_ADL-12 & Moving outdoors using the vehicle without asistance & -2.198 & 0.219 & 0.652 & 0.178 \\
\hline & P_ADL-13 & Talking to young people from oneself & -2.039 & 0.200 & 0.624 & 0.170 \\
\hline & P_ADL-14 & Joining the town association & -1.793 & 0.159 & 0.536 & 0.136 \\
\hline & P_ADL-15 & Playing sports & -1.414 & 0.138 & 0.794 & 0.130 \\
\hline \multirow{14}{*}{$\begin{array}{l}\text { Motor } \\
\text { function } \\
\text { ADL }\end{array}$} & M_ADL-1 & Walking without rest for one hour or more & -1.016 & 0.125 & 0.954 & 0.149 \\
\hline & M_ADL-2 & Running without rest for ten minutes or more & -0.035 & 0.073 & 0.595 & 0.086 \\
\hline & M_ADL-3 & Jumping over the ditch of 50 centimeters & -1.665 & 0.189 & 1.277 & 0.178 \\
\hline & M_ADL-4 & Up stairs without using the walls and handrail & -2.358 & 0.380 & 1.660 & 0.313 \\
\hline & M_ADL-5 & Standing up from sitting straight without using hands & -0.915 & 0.117 & 0.961 & 0.147 \\
\hline & M_ADL-6 & One-leg open-eye stand for thirty seconds or more & -0.792 & 0.094 & 0.676 & 0.105 \\
\hline & M_ADL-7 & Standing without hanging on anything with vehicle & -0.930 & 0.127 & 1.148 & 0.168 \\
\hline & M_ADL-8 & Changing clothes while standing & -2.330 & 0.337 & 1.325 & 0.274 \\
\hline & M_ADL-9 & Multiply by one hand and remove a front button of the shirt & -1.469 & 0.144 & 0.743 & 0.133 \\
\hline & M_ADL-10 & Raising and lowering of heavy futon & -1.565 & 0.188 & 1.062 & 0.189 \\
\hline & M_ADL-11 & Carrying the luggage of ten kilograms by ten meters & -1.249 & 0.140 & 0.936 & 0.145 \\
\hline & M_ADL-12 & Sitting up without using hands five times or more & 0.082 & 0.070 & 0.495 & 0.080 \\
\hline & M_ADL-13 & Up stairs to the fourth floor without rest & -0.456 & 0.113 & 1.438 & 0.201 \\
\hline & M_ADL-15 & Standing up from a squat posture without using hands & -1.586 & 0.242 & 1.524 & 0.265 \\
\hline
\end{tabular}




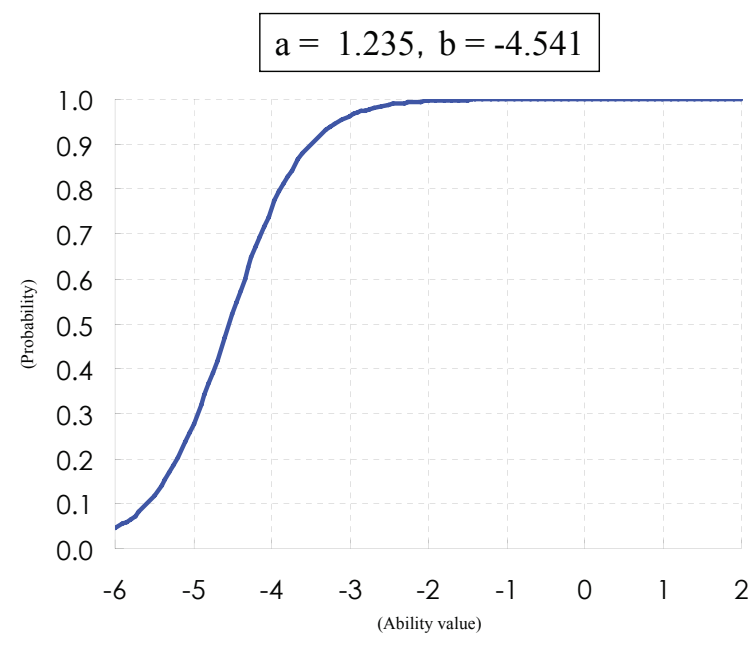

Figure 1 Item characteristic curve (Item:P_ADL-3)

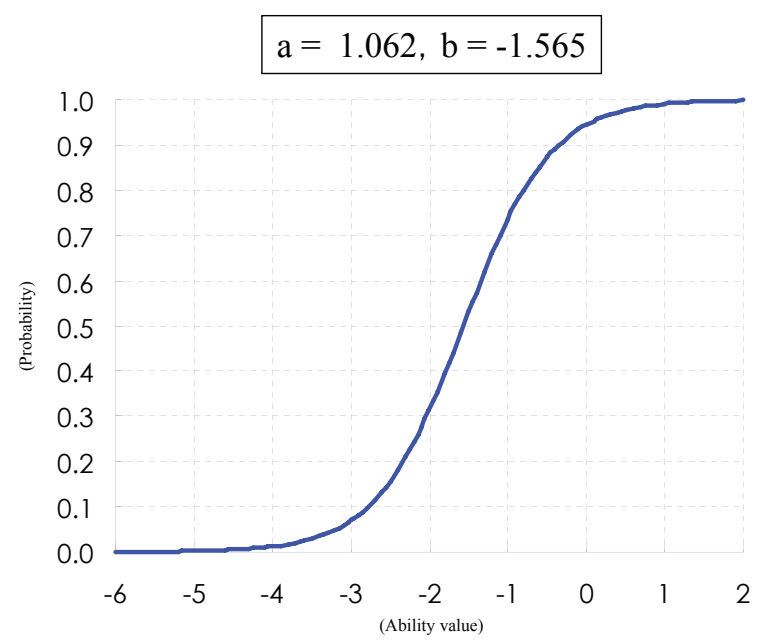

Figure 2 Item charcteristic curve (Item: M_ADL-10)

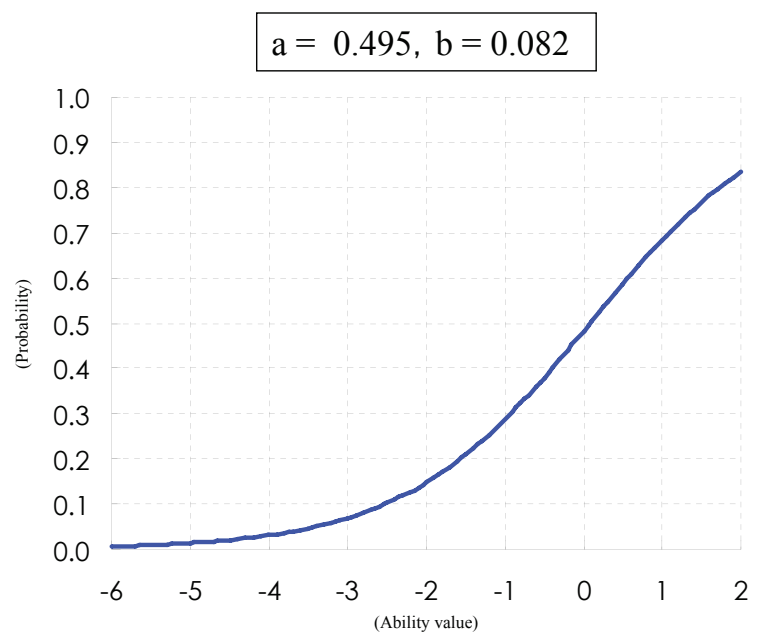

Figure 3 Item characteristic curve (Item:M_ADL-12)

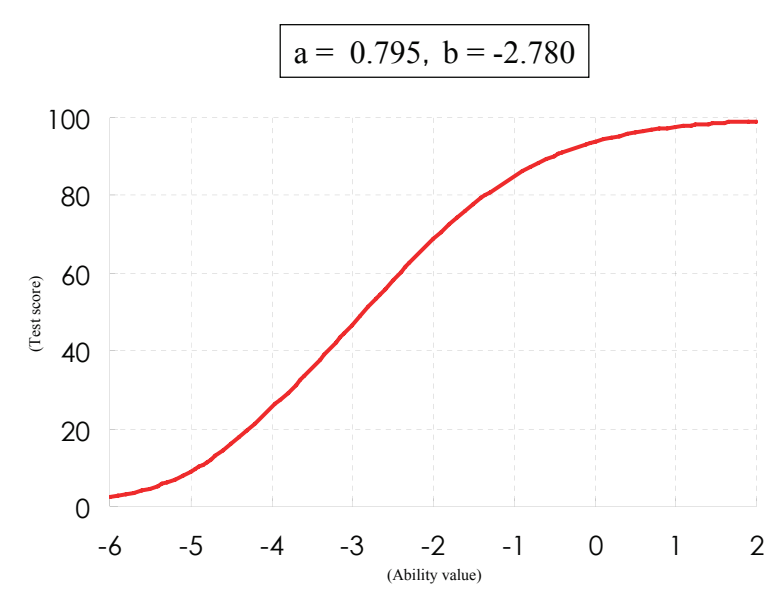

Figure 4 Test characteristic curve (Physical independence ADL Test)

independence ADL were low (below -1) in the item difficulty. Some difference was observed in discrimination power. In motor function ADL, the maximum item difficulty was 0.082 . It had more than 1.5 difference in average compared with items of physical independence ADL. Similarly, discrimination power was relatively high. The ICC of physical independence ADL-3, motor function ADL-10, and motor function ADL-12, which represent a typical shape, are shown in Figure 1 to Figure 3. Physical independence ADL-3 had a curve with a large slope and a shift to the left, which showed that the item difficulty was quite low while its item discrimination power was high. Meanwhile, motor function ADL-12 showed a shape in contrast to physical independence ADL-3. Motor function ADL-10, which was average in item difficulty and item discrimination power, showed an average shape in its curve in all items.

\subsection{Test Characteristic}

The TCC of the physical independence ADL test (perfect score $=100$ points) is shown in Figure 4. The test difficulty was -2.780 , which confirms that it was quite an easy achievable test. The TCC of the motor function ADL test (perfect score $=100$ 


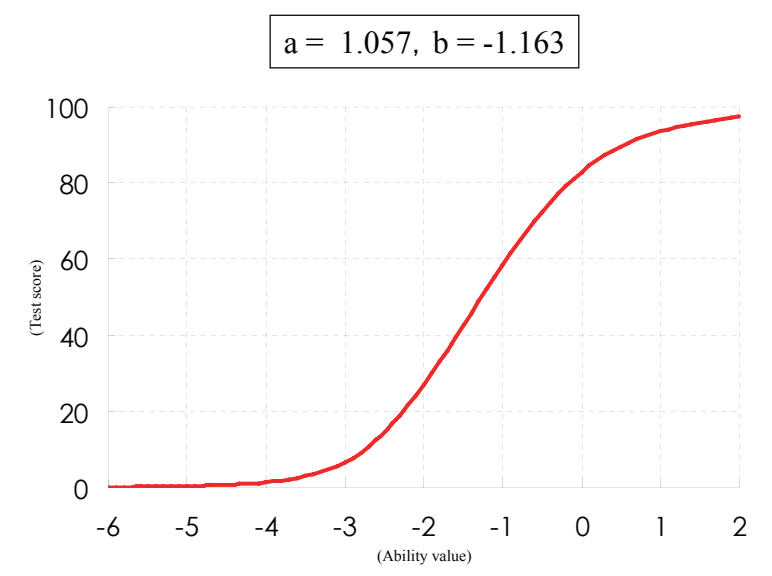

Figure 5 Test characteristic curve (Motor function ADL Test)

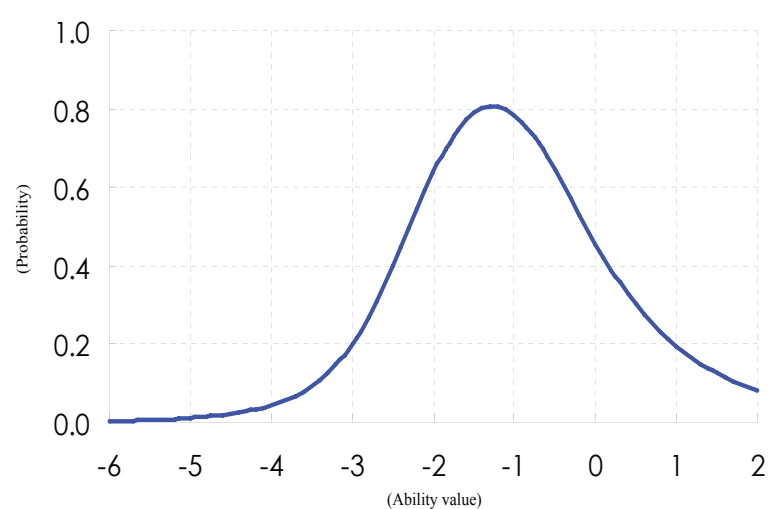

Figure 7 Test information function (Motor function ADL Test)

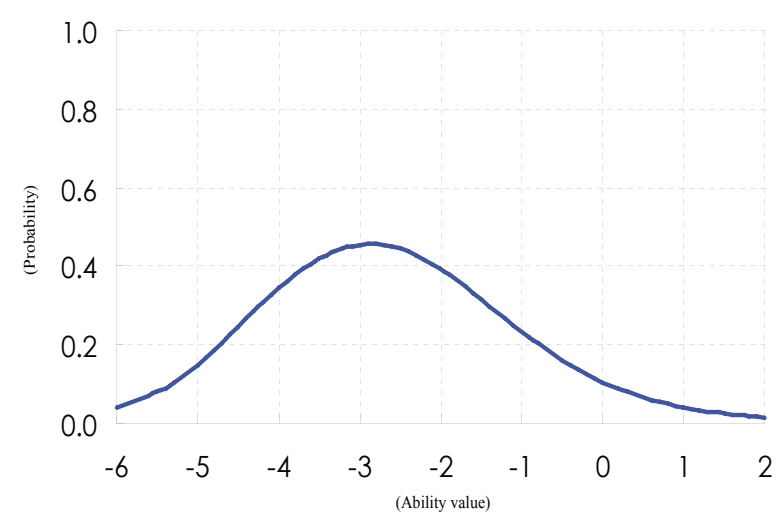

Figure 6 Test information function (Physical independence ADL Test)

points) is shown in Figure 5. The test difficulty was -1.163 , which confirms that it was more difficult to achieve than the physical independence ADL test. The TIF in each test is shown in Figure 6 and Figure 7. The amount of information was small in the physical independence ADL test while the motor function ADL test showed a great amount of information with the ability value around -2 to 0 .

\subsection{Test Creation}

In the present study, with a purpose to examine the possibility of creating a new test on the basis of IRT, we tried to create a new test that could be achievable more than $80 \%$ by almost $70 \%$ of the participants. Table 7 shows the items that

Table 7 Item parameter of newly test

\begin{tabular}{|c|c|c|c|c|c|c|}
\hline Domain & $\begin{array}{c}\text { Item } \\
\text { number }\end{array}$ & Question & $\begin{array}{c}\text { Item } \\
\text { difficulty }\end{array}$ & $\begin{array}{c}\text { Standard } \\
\text { error }\end{array}$ & $\begin{array}{c}\text { Item } \\
\text { discriminati }\end{array}$ & $\begin{array}{l}\text { Standard } \\
\text { error }\end{array}$ \\
\hline \multirow{7}{*}{$\begin{array}{c}\text { Physical } \\
\text { independence } \\
\text { ADL }\end{array}$} & P_ADL-1 & Getting up from the bed without asistance & -3.549 & 0.574 & 0.835 & 0.384 \\
\hline & P_ADL-2 & Changing clothes & -3.015 & 0.356 & 0.735 & 0.230 \\
\hline & P_ADL-5 & Washing clothes & -2.452 & 0.228 & 0.490 & 0.146 \\
\hline & P_ADL-6 & Preparing meal & -2.146 & 0.188 & 0.591 & 0.133 \\
\hline & P_ADL-10 & Doing storoll and physical exercise & -3.187 & 0.399 & 0.885 & 0.228 \\
\hline & P_ADL-12 & Moving outdoors using the vehicle without asistance & -2.198 & 0.219 & 0.652 & 0.178 \\
\hline & P_ADL-14 & Joining the town association & -1.793 & 0.159 & 0.536 & 0.136 \\
\hline \multirow{8}{*}{$\begin{array}{c}\text { Motor } \\
\text { function } \\
\text { ADL }\end{array}$} & M_ADL-1 & Walking without rest for one hour or more & -1.016 & 0.125 & 0.954 & 0.149 \\
\hline & M_ADL-2 & Running without rest for ten minutes or more & -0.035 & 0.073 & 0.595 & 0.086 \\
\hline & M_ADL-4 & Up stairs without using the walls and handrail & -2.358 & 0.380 & 1.660 & 0.313 \\
\hline & M_ADL-6 & One-leg open-eye stand for thirty seconds or more & -0.792 & 0.094 & 0.676 & 0.105 \\
\hline & M_ADL-8 & Changing clothes while standing & -2.330 & 0.337 & 1.325 & 0.274 \\
\hline & M_ADL-10 & Raising and lowering of heavy futon & -1.565 & 0.188 & 1.062 & 0.189 \\
\hline & M_ADL-11 & Carrying the luggage of ten kilograms by ten meters & -1.249 & 0.140 & 0.936 & 0.145 \\
\hline & M_ADL-13 & Up stairs to the fourth floor without rest & -0.456 & 0.113 & 1.438 & 0.201 \\
\hline
\end{tabular}


compose the new test. The number of items used to create the new test was 15 , which were selected based on the item difficulty and the item discrimination power. The test difficulty of the created test was -1.876 , and the test discrimination power was 0.891 . Thus, we could prepare a new test that conformed to the target level.

\section{Discussion}

\subsection{Item Character}

The mean passive rate for items of the physical independence ADL was extremely high with $96 \%$. It was assumed that they were improper as measuring items of daily living activities of the active elderly. Especially, since the item 'Down stairs without assistance' was $100 \%$ in the passive rate, it was judged as useless for assuming the ability. The mean of the item difficulty was -2.78 , which implies that only the subjects whose deviation score was 20 to 25 could not achieve the physical independence ADL test. From this fact, it was clear that the items of physical independence ADL were inappropriate to measure daily living activities of the active elderly. The item discrimination power of physical independence ADL-3 and physical independence ADL-9 was below 1.0. From the fact that the item difficulty was also extremely low, it was indicated that functional disorder was probably present if these items could not be achieved. On the contrary, the item character of physical independence ADL-15 showed that it was the item for measuring high-level ADL. These results accorded with the purpose of measuring the remaining abilities of disabled elderly and functional recovery in rehabilitation when the ADL test was created [Barer and Nouri, (1989)].

The mean passive rate of motor function ADL was $77 \%$, which is appropriate in measuring basic daily living activities that corresponds to different living conditions of the active elderly. When the item difficulty was taken into consideration, the of deviation score for achievement motor function $\mathrm{ADL}$ was approximately 40, which was considered to be the target level of basic daily living activities.

The item discrimination power was high, when compared with the items of physical independence ADL. Therefore, the items of motor function ADL were judged to be proper in discriminating subjects who have almost equal ability with the item difficulty. Some items, like motor function ADL-12, had an item difficulty of more than 0 . In these items, achievement rate is less than $50 \%$ in the subjects with standard deviation of 50. Such items were thought to be slightly too high as achievement target level in the elderly.

\subsection{Test Characteristic}

We examined test characteristic. From Figure 4, it was confirmed that the physical independence ADL test was able to achieve 50\% in subjects with the ability value, $\theta=-2.780$. The TCC showed that the level of the ability value should be more than $\theta=-1.3$ to make the test achievement rate $80 \%$. This ability value was 37 if expressed in the deviation score, which was rather low so it was assumed that approximately $80 \%$ of all the subjects could achieve it. Figure 5, when observed in the same view, shows that the ability level to achieve $80 \%$ of the motor function $\mathrm{ADL}$ test was $\theta=-0.1$. It is 49 in the deviation score, and the test can be achieved by the subjects who have average ability. From the above results, it is supposed that only a little over $50 \%$ of all is achievable.

As for the TIF of Figure 6 and Figure 7, in the physical independence ADL test, an ability value around $\theta=-3$ was high in the amount of information in the test. Therefore, the test was thought to be sensitive to the elderly whose level of physical strength was extremely low. The motor function ADL test appeared to be appropriate to classify subjects with the ability level around $\theta=-1.5$. 


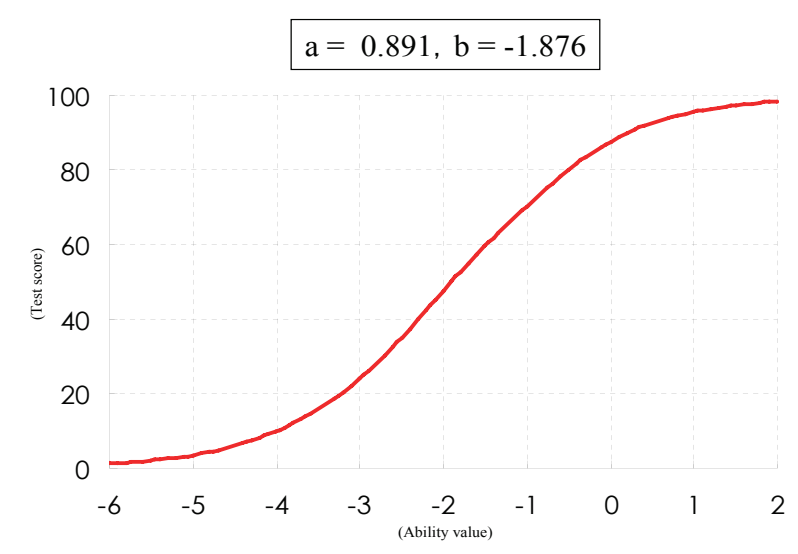

Figure 8 Test characteristic curve (The test created newly)

\subsection{Test Creation}

Figure 8 shows the TCC and Figure 9 shows the TIF of the newly test. It was confirmed from the TCC that we constructed a test achievable by approximately $70 \%$ in subjects with the ability value, $\theta=-1.0$. TIF showed a balanced distribution with an ability level of $\theta=-1.9$ in its center. The TIF showed that the test was sensitive to the subjects in the range of the ability level, $\theta=-1.0$ to -3.0. These results suggest that it is possible to create tests appropriate to their target level or their purpose based on the item character. Preparation of items that are varied in item difficulty and item discrimination power permits creation of tests in accordance with the level of subjects. It enables the creation of an ADL test to measure a wide range of abilities of the elderly. The stance of the present study was to work toward creating an adaptive test for measuring ADL. For future study, we hope to create an adaptive test that is easily measurable with a small number of items by clarifying item characters of other relevant test [Shibayama, et al., (1987)].

\section{References}

Asberg, K. H., and Sonn, U. (1988) The cumulative structure of personal and instrumental ADL. Scandinavian Journal of Rehabilitation Medicine 21: 171-177.

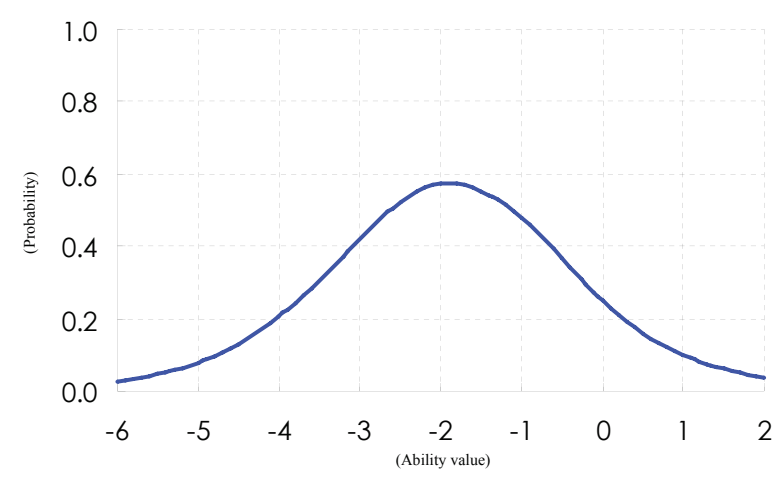

Figure 9 The information function (The test created newly)

Barer, D., and Nouri, F. M. (1989) Measurement of activities of daily living. Clinical Rehabilitation 3: 179-187.

Fillenbaum, G. G. (1985) Screening the elderly: A brief instrumental activities of daily living measure. Journal of American Geriatric Society 33: 698-706.

Hambleton, R. K., and Swaminathan, H. (1985) Item response theory. Kluwer, Nijhoff, Boston: pp.10-13.

Hattori, T. (1986) Method of simultaneous equating for scales with the Rash model using common-item technique. The Japanese Journal of Behavormetrics 14(1): 39-46. (in Japanese with English abstract)

Jette, A. M., and Branch, L. G. (1981) The Framingham disability study: physical disability among the aging. American Journal of Public Health 71: 1211-1216.

Katz, S., Ford, A. B., Moskowitz, R. M., Jackson, B. A., and Jaffe, M. W. (1963) Studies of illness in the aged: The index of ADL: A standard measure of biological and psychosocial function. The journal of American Medical Association 185: 914-919.

Katz, S., Downs, T. D., Cash, H. R., and Grotz, R. C. (1970) Progress in development of the index of ADL. Gerontologist 10(1): 20-30.

Kempen, G., and Suurmeijer, J. (1990) The development of a hierarchical polychotomous ADL-IADL scale for noninstitutionalized elders. Gerontologist 30: 497-502.

Lord, D. N. (1952) A theory of test score. Psychometoric Monograph 7, Psychometoric society.

Lawton, M. P., and Brody, E. M. (1969) Assessment of older people: Self-maintaining and instrumental activities of daily living. Gerontologist 9: 179-186.

Lawton, M. P. (1970) Assessment, integration, and environments for older people. Gerontologist 10(1): 38-46.

Mahoney, F. I., and Barthel, D. W. (1965) Functional evaluation: the Barthel index. Maryland State medical journal 14: 61-65.

Meer, B. and Baker, J. A. (1966) The Stockton geratric rating scale. Journal of Gerontologyt 21: 392-403.

Ohtomo, K., Asano, H., Hattori, T. and Yoshie, M. (1987) Item difficulty of English language tests for Japanese students. Japan Association of College English Teachers bulletin 18: 109-125. 
Pfeffer, R. I., Kurosaki, T. T., Harrach, C. H., Chance, J. M., and Filos, S. (1982) Measurement of functional activities in older adults in the community. Journal of Gerontology 37: 323-329.

Potivin, A. R. and (1972) Simulated activities of daily living examination. Archives of Physical Medicine and Rehabilitation. 53: 476-486.

Rasch, G. (1960) Probabilistic models for some intelligence and attainment tests. Danish Institute for Educational Research.

Rusk, H. A. (1977) Rehabilitation Medicine. A textbook of physical medicine and rehabilitation. CV Mosby, Saint Louis: pp.16-23.

Shibayama, T., Noguchi, H., Shiba, S., and Kamahara, M. (1987) An adapting testing procedure for measuring verbal ability. Japanese Journal of Educational Psychology. 35: 363-367. (in Japanese with English abstract)

Sonn, U., and Asberg, K. H. (1999) Assessment of activities of daily living in the elderly. Scandinavian Journal of Rehabilitation Medicine 23: 193-202.

Spector, W. D., Katz, S., Murphy, J. B., and Fulton, J. P. (1987) The hierarchical relationship between activities of daily living and instrumental activities of daily living. Journal Chronic Diseases 40: 481-489.

Spector, W. D., and Fleishman, J. A. (1998) Combining activities of daily living with instrumental activities of daily living to measure functional disability. Journal of Gerontology. 53B(1): S46-S57.

Takane, Y. and Leeuw, J. (1987) On the relationship between item response theory and factor analysis of discretized variables. Psychometorika. 52(3): 393-408.

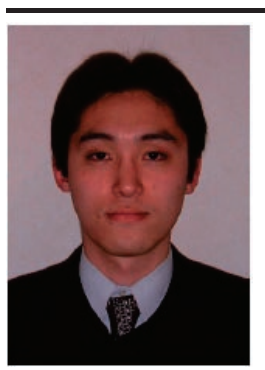

Name:
Takahiro Nakano

Affiliation:

Doctoral Program in Health and Sports Sciences, University of Tsukuba

Address:

1-1-1 Tennodai, Tsukuba, Ibaraki 305-8574 Japan

Brief Biographical History:

1998- Doctoral Program in Health and Sport Sciences, University of Tsukuba

2003- Received Ph.D at Unversity of Tsukuba

2003- Researcher (COE), Doctoral Program in Health and Sport Sciences, University of Tsukuba

2004- Researcher (COE), Doctoral Program in Health and Sport

Sciences, University of Tsukuba

Main Works:

- "Factor structural analysis of condition fluctuation by dynamic factor analysis"Japan Journal of Physical Education, Health and Sport Sciences, Vol.48(4). 369-381. July. (2003)

- "Dynamic Factorial Structure of Perceived Condition for a Women's Competitive Walker'International Journal of Sport and Health Sciences, Vol.2. 67-75. (2004)

Membership in Learned Societies:

- Japan Society of Physical Education, Health and Sport Sciences

- Japan Society of Physical Fitness and Sports Medicine

- American College of Sports Medicine 